\title{
28 Research Square \\ Gemcitabine-Resistance Reversion of Cucurmosin in Human Pancreatic Cancer Cells
}

Congfei Wang

Fujian Medical University Union Hospital

Mingjuan Fu

Matemity and Child Health Care of Zaozhuang

Heguang Huang ( $\square$ huanghg1962@163.com)

Fujian Medical University Union Hospital https://orcid.org/0000-0002-0665-9178

Jieming Xie

Fujian Medical University

\section{Research Article}

Keywords: cucurmosin, pancreatic cancer, gemcitabine-resistance cell, proliferation inhibition, resistance reversion

Posted Date: July 23rd, 2021

DOl: https://doi.org/10.21203/rs.3.rs-722308/v1

License: (1) (1) This work is licensed under a Creative Commons Attribution 4.0 International License. Read Full License 


\section{Abstract}

Objective To investigate the effects of cucurmosin (CUS) on proliferation and drugs resistance in gemcitabine (GEM) human pancreatic cancer cell PANC-1RG7.

Methods The ultrastructural changes of PANC-1RG7 cells after CUS intervention were observed by transmission electron microscope. Flow Cytometer (FCM) was used to detect the effect of CUS on the growth cycle of PANC-1RG7 cells. We used colony formation experiment, Sulforhodamine B assays and subcutaneous implantation tumor model to observe the proliferation inhibition and reversal drugresistance reversion of CUS on PANC-1RG7 in vitro and in vivo. Western blot was used to observe the expressions of RRM1, RRM2, PI3K, Akt, mTOR and other proteins related to apoptosis after CUS intervention.

Results After CUS intervention, PANC-1RG7 cells were obviously apoptotic with large number of vacuoles and apoptotic bodies. Compared with parental cell PANC-1, GEM-resistant cell PANC-1 was more sensitive to CUS. The combination of GEM and CUS at different concentrations showed synergistic effect. At the concentration of CUS with the inhibition rate of $10 \%$, the reversal multiples and the reversal efficiency were $1.78 \pm 0.65$ and $50.13 \pm 16.87 \%$, respectively. Subcutaneous implantation tumor model confirmed the proliferation inhibitory effect of CUS in vitro. Western blot confirmed that CUS down-regulated the expressions of RRM1, RRM2, PI3K, Akt and mTOR.

Conclusion CUS can significantly inhibit PANC-1RG7 cell proliferation in vivo and in vitro, and can reverse cell GEM-resistance.

\section{Introduction}

Resection is still the main treatment for pancreatic cancer, but the prognosis of patients with pancreatic cancer is difficult to improved due to low resection rate and high relapse rate. Chemotherapy, which is an important part of comprehensive treatment for pancreatic cancer, is the main treatment to improve the survival rate of patients after surgery and patients who have lost the surgery opportunity [1]. Gemcitabine (GEM) has been recommended by the FOOD and Drug Administration as a first-line chemotherapy drug for pancreatic cancer since 1997. GEM-based combination chemotherapy regimens were the main direction of researches in the past 20 years, among which GEM combined with albumin paclitaxel has made great progress. So GEM still remains unchallenged position. But the effect of GEM improving the clinical benefit and survival of patients is still limited because of the inherent and secondary drug resistance problem. Thus, finding a new drug with high effectiveness and low toxicity, that can synergize with existing chemotherapeutic drugs or reverse their resistance, is important.

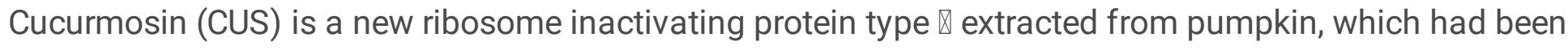
shown to inhibit the growth of pancreatic cancer cells significantly, induce their apoptosis and downregulate several signaling pathways, including apoptose-related AKT/mTOR, EGFR, PDGFR and so on [25]. This study aimed to observe the cell proliferation inhibition and drug resistance reversion induced by 
CUS in the GEM-resistance pancreatic cancer cell line for providing theoretical and experimental basis for the potential clinical application of CUS in anti-pancreatic cancer.

\section{Materials And Methods}

\section{Cell culture, animal feeding, and intervention drugs}

The GEM-resistance human pancreatic cancer cell line PANC-1G7 was established in vitro by gradually increasing GEM concentrations and cloning cell cultures by our research group using PANC-1 [6], which is the most common and poorly differentiated cell line derived from human pancreatic ductal carcinomain. The resistance index of PANC-1RG7 to GEM is 39.9. We incubated the cells with RPMI $1640+15 \%$ fetal bovine serum (Gibco) at $37{ }^{\circ} \mathrm{C}$ in a $5 \% \mathrm{CO} 2$ cell incubator (3110, Thermo Scientific). The cells were digested by $0.25 \%$ trypsinogen (Gibco) $+2 \%$ Ethylene Diamine Tetraacetic Acid for passage with 1:2-4 once every $2 \mathrm{~d}$ to $3 \mathrm{~d}$. Male nude mice were obtained from the Animal Center of the Peking Union Medical College, China. The mice were fed in a specific pathogen free-grade animal room at Fujian Medical University Animal Center following aseptic principles strictly. All experimental procedures on animals were approved by the Institutional Animal Care and Use Committee at Fujian Medical University. CUS with a purity of $97 \%$ was quantified used by bicinchoninic acid (BCA) protein assay. Then, the proteins were split charged after filter sterilization and kept in $-20^{\circ} \mathrm{C}$ before use. GEM (Hengda Pharmaceutical Co., Ltd., Shanxi, China) was dissolved in normal saline to obtain a final concentration of $100 \mathrm{mmol} / \mathrm{L}$ and stored at $-20{ }^{\circ} \mathrm{C}$.

\section{Cellular shape changes by transmission electron microscope}

PANC-1RG7 cells in logarithmic phase $\left(3 \times 10^{5} /\right.$ well) were seeded in 6-well plates. After incubation for 24 h, cells were treated with $0.5 \mu \mathrm{mol} / \mathrm{L}$ CUS for $72 \mathrm{~h}$. Control cells were supplemented with RPMI- 1640 culture medium. Cells $\left(1 \times 10^{6}\right)$ were harvested and washed 3 times with PBS, then centrifuged at $15,000 \mathrm{~g}$ for $15 \mathrm{~min}$, and subsequently fixed in $4 \%$ glutaraldehyde for $2 \mathrm{~h}$. After fixation, samples were fixed in $1 \%$ osmic acid for $2 \mathrm{~h}$, then gradually dehydrated by acetone and embedded with epoxy resin. Cellular shape were observed under transmission electron microscope.

\section{Cell cycle and apoptosis analysis by flow cytometry}

PANC-1 RG7 cells in logarithmic phase $\left(5 \times 10^{6} /\right.$ well) were seeded in 6-well plates. After incubation for 24

$\mathrm{h}$, cells were treated without or with 0.5 and $0.125 \mu \mathrm{mol} / \mathrm{L}$ CUS for $72 \mathrm{~h}$. Cells $\left(1 \times 10^{6}\right)$ were harvested and washed 3 times with PBS, and then respectively analyzed for their DNA content and apoptosis ratio by ACSCalibur (Becton-Dickinson, Mountain View, CA) using Cell Cycle Detection kit and Annexin V-FITC Apoptosis Detection kit (KeyGEN, Nanjing, China) according to the protocol of the manufacturer.

\section{Sulforhodamine B (SRB) assays}


PANC-1RG7 cells in logarithmic phase $\left(15 \times 10^{2} /\right.$ well $\left.\times 150 \mu \mathrm{L}\right)$ were seeded in 96 -well culture plates and incubated for $24 \mathrm{~h}$ until adherence. Then, the cells were treated with $\operatorname{GEM}(2,1,0.5,0.25,0.0125,0.0625$, 0.013125 and $0.015625 \mu \mathrm{mol} / \mathrm{L})$, CUS $(0.03125,0.0625,0.125,0.25,0.5,1$, and $2 \mu \mathrm{mol} / \mathrm{L})$, and CUS combined with GEM at different concentrations (shown in the results). The cells were incubated $96 \mathrm{~h}$ before the supernatant was removed. We added $100 \mu \mathrm{L} /$ well of precooled trichloroacetic acid for more than $1 \mathrm{~h}$ of fixation at $4{ }^{\circ} \mathrm{C}$ away from light. We used $50 \mu \mathrm{L} /$ well of SRB liquor $(0.4 \%$ SRB and $1 \%$ acetic acid) to dye the plates for 15 min after washing five times with ddH2O. We dissolved $150 \mu \mathrm{L} /$ well of 10 $\mathrm{mmol} / \mathrm{L}$ Tris for $5 \mathrm{~min}$ after washing five times with $1 \%$ acetic acid. Colorimetry was performed at $570 \mathrm{~nm}$ with a Multiskan MK3 Microplate Reader (Thermo Scientific). The dose-/time-effect curve of GEM, CUS, or both were plotted to calculate for $50 \%$ inhibiting concentration (IC50).

The inhibition rates of GEM, CUS, and CUS combined with GEM at different concentrations in PANC-1RG7 were calculated, and The King's formula was used to determine whether the combination of GEM and CUS had synergistic effect on cell proliferation inhibition. King's formula: $Q=E_{A+B} /\left(E_{A}+E_{B}-E_{A} \times E_{B}\right)$, in which $E_{A}$ and $E_{B}$ represent the inhibition rate of drug $A$ and drug $B$ respectively, the numerator represents the measured combined effect, the denominator represents the expected combined effect, and $Q$ is the ratio of the two. $Q=0.85-1.15$ is the addition (+), $Q=1.15-2.0$ is the synergy $(++), Q>2.0$ is the obvious synergy $(+++), Q=0.85-0.55$ is the antagonism (-), and $Q<0.55$ is the obvious antagonism (-).

The reversal multiple and relative reversal efficiency were calculated after intervention with different concentrations of GEM combined with CUS. The CUS concentration was $0.007813 \mu \mathrm{mol} / \mathrm{L}$, in which the inhibition rate of PANC-1RG7 treated with CUS alone was $10 \%$. The reversal multiple $=$ resistant strain IC50/ IC50 after reversal. The relative reversal efficiency (\%) = (IC50 before reversal - IC50 after reversal) $/($ IC50 before reversal - parent strain IC50) $\times 100$.

\section{Cell colony formation}

PANC-1RG7 cells in logarithmic phase (300/well) were seeded in 24-well culture plates and incubated for $24 \mathrm{~h}$ until adherence. Then, the cells were treated with CUS (0.003125 and $0.0125 \mu \mathrm{mol} / \mathrm{L}), \operatorname{GEM}(0.4,0.1$, and $0.0025 \mu \mathrm{mol} / \mathrm{L}$ ), and CUS combined with GEM at different concentrations (shown in the results). The control cells were supplemented with RPMI- 1640 culture medium to maintain the same volume. The cells were dyed with Giemsa stain for 5 min after $14 \mathrm{~d}$, whereas the cell colony had more than 50 cells. The cells were washed with water and then counted. Colony inhibitory rate $(\%)=(1$-positive colony number/negative colony number) $\times 100$. We also used Jin's formula to evaluate the combined effect.

\section{Establishment of animal models and drug intervention}

PANC-1RG7 cells ( $3 \times 10^{7}$ cells suspended in $50 \mu \mathrm{L}$ of RPMI1640) were injected percutaneously using a hypodermic needle on the back of the mice using a 29-gauge syringe. A total of 30 integrated mice with tumor grown to approximately $0.4 \mathrm{~cm}$ in diameter were divided into three groups: 10 in Control group (injected intraperitoneally with $10 \mathrm{~mL} / \mathrm{kg}$ normal saline on Days 15, 18, 21, 24, 27 and 30); 10 in CUS high-dose group (injected intraperitoneally with $1 \mathrm{mg} / \mathrm{kg}$ CUS on Days 15, 18, 21, 24, 27 and 30) and 10 in 
CUS low-dose group (injected intraperitoneally with $0.5 \mathrm{mg} / \mathrm{kg}$ CUS on Days 15, 18, 21, 24, 27 and 30). At the same time, PANC-1 cells had been processed in the same way. We observed the general condition of the mice and tumors after execution on Day 33.

\section{Western blot}

After treatment without or with 0.125 and $0.5 \mu \mathrm{mol} / \mathrm{L}$ CUS for $72 \mathrm{~h}$, the PANC-1RG7 cells were harvested and washed three times with PBS. Before being centrifuged at 12,000 $\mathrm{g}$ for $10 \mathrm{~min}$, each sample was lysed in lysis buffer (50 mmol/L Tris-HCl, pH 7.5, 0.15 mol/L NaCl, 1\% Na-deoxycholate, 1 mmol/L EDTA, $1 \%$ Triton $\mathrm{X}-100,0.1 \%$ sodium dodecyl sulfate, and $1 \mathrm{mmol} / \mathrm{L}$ phenylmethylsulfonyl fluoride) by $15 \mathrm{~min}$ of incubation at $4{ }^{\circ} \mathrm{C}$. Protein concentrations were measured by BCA assay. Total proteins, modified with $5 \times$ buffer in $95^{\circ} \mathrm{C}$ for $5 \mathrm{~min}$, were fractionated by SDS-polyacrylamide gel electrophoresis (SDS-PAGE) and then transferred onto 0.22 micron polyvinylidene difluoride membranes. The membranes were blocked using 5\% BSA and then incubated with specific primary antibodies: mouse monoclonal antibodies antihuman $\beta$-actin (No. AA128-1, Beyotime Institute of Biotechnology, China), Akt (No. BS1810, BioWorld, USA), and mTOR (No. BS3611, BioWorld, USA); rabbit monoclonal antibodies anti-human PI3K (No. 4249, Cell Signaling Technology, USA); goat polyclonal antibodies anti-human RRM1 (No. sc-11733, Santa Cruz, USA) and RRM2 (No. sc-10846, Santa Cruz, USA). After being washed thrice (5 min each) with TBST, the membranes were incubated with goat anti-mouse/rabbit IgG antibody labeled by horseradish peroxidase (No. A0216/A0208, Beyotime Institute of Biotechnology, China) for $1 \mathrm{~h}$ and then washed with TBST, reacted with ECL (Lu Long, China) for 5 min, exposed developed, rinsed and fixed. Images were analyzed using Quantity One 4.62.

\section{Statistical analysis}

Experimental data were presented as mean \pm standard deviation $(\overline{\boldsymbol{x}} \pm$ SD) and analyzed by SPSS 19.0. Two groups were analyzed by t-test, whereas one-way ANOVA and least significant difference test were used for multiple-group analysis and multiple comparisons, respectively. $\mathrm{P}<0.05$ and $\mathrm{P}<0.01$ were considered to indicate significant difference and highly significant difference, respectively.

\section{Results}

\section{Morphological and ultrastructure characteristics}

Transmission electron microscopy was used to examine cellular shape to evaluate whether CUS inhibited the proliferation in PANC-1RG7 cells through induction of apoptosis. After PANC-1RG7 cells were treated with $0.5 \mu \mathrm{mol} / \mathrm{L}$ CUS for $72 \mathrm{~h}$, the cellular volume and the microvilli on the cell membrane were significantly reduced, the surface protuberances were increased, the cytoplasm and the nucleus were condensed, the cytoplasm was deeply stained, the endoplasmic reticulum was expanded obviously, the mitochondria was swollen, the nuclear membrane was sunken, and a significant number of vacuolus and apoptotic bodies were observed in cells (Figure 1). 


\section{Cell cycle analysis by flow cytometry}

After PANC-1RG7 cells were treated with CUS in different concentrations for $72 \mathrm{~h}$, there was no significant change in the cell ratio in $G 0 / G 1, S$ or $G 2 / M$ phase with different drug concentrations ( $p>0.05$ ). The distribution histogram of DNA (Figure 2) showed a subdiploid peak (i.e., apoptotic peak) appeared before the diploid peak in PANC-1RG7 cells after $0.5 \mu \mathrm{mol} / \mathrm{L}$ CUS intervention for 72 hours. The apoptosis rates of each group with $0,0.125$ and $0.5 \mu \mathrm{mol} / \mathrm{L}$ CUS were $1.39,4.31$ and $31.89 \%$, respectively, which gradually increased with the drug dose.

\section{SRB assays}

The IC50 of CUS for inhibiting PANC-1 and PANC-1RG7 cells were $0.0535 \pm 0.0100$ and $0.0318 \pm 0.0090$ $\mu \mathrm{mol} / \mathrm{L}$ with significant differences $(\mathrm{P}<0.05)$.

The combination treatment of CUS combined with GEM for $96 \mathrm{~h}$ showed higher inhibitory rate than either treatment alone. But the $\mathrm{Q}$ values were all in the range of $0.85-1.15$ indicating that the effect was only addition effect but no synergistic or antagonistic action (Table 1).

The IC50 of GEM for inhibiting PANC-1RG7 cells were $0.1136 \pm 0.035 \mu \mathrm{mol} / \mathrm{L}$ combined with 0.007813 $\mu \mathrm{mol} / \mathrm{L}$ CUS, in which the inhibition rate of PANC-1RG7 treated with CUS alone was $10 \%$. The reversal multiple and efficiency of this concentration of CUS were $1.78 \pm 0.65$ and $50.13 \pm 16.87 \%$, respectively, indicating that low concentration of CUS had a certain reversal effect on the resistance of GEM in PANC1 RG7.

\section{Cell colony formation}

We observed that the cell colony numbers decreased significantly after treatment with CUS or GEM (Figure 3) in a dose-dependent manner. PANC-1 cells failed to form colonies, while PANC-1RG7 cells could form a few colonies after the intervention of $0.0025 \mu \mathrm{mol} / \mathrm{L}$ GEM, showing resistance to GEM in PANC1RG7. In contrast, PANC-1RG7 cells failed to form colonies, while PANC-1 cells could form a few colonies after the intervention of $0.01 \mu \mathrm{mol} / \mathrm{L}$ CUS. Therefore, it can be preliminarily determined that PANC-1RG7 is more sensitive to CUS than its parent cells (Figure 3). All the Q values were in the range of $0.85-1.15$, which showed only addition effect but no synergistic or antagonistic action (Table 2).

\section{Animal models}

We successfully established nude mouse subcutaneous tumor models. All 60 remaining mice were killed on Day 33. Subcutaneous tumors were completely peeled off and weighed. CUS can inhibit PANC-1 and PANC-1RG7 cell growth in a dose-dependent manner in vivo (Figure 4, Table 3). Compared with PANC-1, PANC-1RG7 had higher inhibition rates of the tumors, indicating that CUS inhibited GEM-resistant cell line PANC-1RG7 more than its parent cell (Table 4).

\section{Western blot}


After intervention of $0,0.125$, and $0.5 \mu \mathrm{mol} / \mathrm{L}$ CUS for $72 \mathrm{~h}$, the expression levels of RRM1, RRM2, PI3K, Akt, and mTOR in the treated PANC-1RG7 cells decreased in a dose-dependent manner (Figure 5), showing that CUS can down-regulate the expression of RRM1 and RRM2 to increase the sensitivity of PANC-1RG7 to GEM, and finally induce cell apoptosis by regulating protein expression in the antiapoptotic pathway PI3K/Akt/mTOR.

\section{Discussions}

CUS, which has a variety of biological activities such as anti-virus, anti-fertility and anti-tumor, prevents elongation factors from binding to ribosomes to inhibit protein biosynthesis at the protein level [7]. After intervention of CUS, apoptotic was observed by electron microscope and apoptotic peak was also observed by flow cytometry in PANC-1RG7 cells obviously, which was consistent with the previous research results that CUS could induce apoptosis of pancreatic cancer cells $[4,8-10]$. Previous experiments also found that CUS could cause DNA damage and block PANC-1 cells in G0G1 phase [8]. However, the cell cycle arrest effect of CUS on PANC-1RG7 was not observed in this study. The rate changed in each period without statistically significant difference, which may be related to the lower intervention concentration of CUS in this study. Experiment results found that CUS had stronger inhibition of proliferation in PANC-1RG7 than its parent cell PANC-1 in vivo and in vitro. The concentration of CUS causing PANC-1RG7 cell death is lower than that significantly blocking PANC-1 cell cycle, may indicating some characteristics of PANC-1RG7 cells change making the cells more vulnerable to CUS poison and the effect is more significant than DNA damage .

In order to observe whether the combined treatment has synergistic effect on PANC-1RG7 cells growth, cells were intervened by combination of CUS and GEM at different concentrations and then SRB assays were proceeded. The results showed that compared with the single drug, the inhibition rate of the combined drug group was significantly increased. But there was no obvious synergistic or antagonistic action observed $(0.85<Q<1.15)$. In the following colony formation experiments, long-acting observations of low-concentration drugs also showed the same results, which may indicate that there is no common pathway in the mechanisms of CUS and GEM.

However, the IC50 of GEM on PANC-1RG7 cells was significantly reduced when it combined with CUS in the concentration of $0.007813 \mu \mathrm{mol} / \mathrm{L}$, in which CUS could inhibited $10 \%$ cell alone. The reversal ratio was $1.78 \pm 0.65$ and the reversal efficiency was $50.13 \pm 16.87 \%$, suggesting that CUS could partially reverse the resistance of GEM in PANC-1RG7 cells. Expressions of RRM1 and RRM2 protein, which are significantly increased compared with their parent cell PANC-1, were significantly reduced in a concentration-dependent manner in PANC-1RG7 cells after CUS intervention. RRM1 and RRM2 can promote the conversion of nucleosides to deoxyribonucleoside triphosphate and accelerate the polymerization and repair of DNA resulting drug resistance [11]. CUS could down-regulate their protein expressions, which is likely one of the reasons why CUS could reverse GEM-resistance of PANC-1RG7. 
$\mathrm{PI}$ KK/Akt/mTOR signaling pathway is an important intracellular signal transduction pathway, and the expressions of related proteins change in most human malignant tumors. Lipid kinase PI3K can specifically phosphorylate the 3-hydroxyl group on the phosphoinositide ring as the initiating factor of this pathway. Its downstream target Akt (also known as protein kinase B) is one of the key proteins in this signaling pathway, and its continuous activation is closely related to the occurrence and development of tumors. The activated Akt transmits signals to several downstream substrates to regulate biological effects such as transcription, translation, and apoptosis. The activated PI3K/Akt further activates the downstream molecule mTOR through the TSC1/2 complex, regulates the downstream translational inhibition molecule ELf-4E binding protein 1 (4E-BP1) and ribosomal protein p70S6 kinase (p70S6K), and finally regulates cell growth and proliferation [12-13]. Tumor cells will be inhibited into the process of apoptosis with drug resistance, being a kind of self-protection to directly affect chemotherapy drugs effect. PI3K/Akt/mTOR signaling pathway is the most important signaling pathway to inhibit cell apoptosis [14]. In this study, we found that the expressions of PI3K, Akt and mTOR proteins in PANC$1 R G 7$ cells were significantly reduced in a concentration-dependent manner after CUS intervention, suggesting that PI3K/Akt/mTOR signal transduction pathway is involved in the process of PANC-1RG7 cell apoptosis induced by CUS.

In conclusion, CUS can induce PANC-1RG7 cell apoptosis by inhibiting PI3K/Akt/mTOR signal transduction pathway and inhibit cell proliferation both in vivo and in vitro, which is more obvious than its parent cell PANC-1. Combined application of CUS and GEM showed additive effect. CUS could partially reverse the GEM-resistance of PANC-1RG7 cells in a low concentration, and the mechanism may be downregulation effect of CUS on RRM1 and RRM2 protein expressions. Since CUS is not a single target drug, it can nonspecific down-regulate the expression of various proteins, so how to improve the targeting of CUS to reduce its usage amount for reducing its toxic and side effects has become an important difficulty needs to be overcome before the clinical application.

\section{Declarations}

\section{Funding}

This study was supported by Natural Science Foundation of Fujian Province, China (No. 2018J05134, 2018J05131 and 2016J01769), Medical Minimally Invasive Center Program of Fujian Province, China (No. 2017-171) and Fujian Province health and family planning scientific research talent training project (No. 2018-CX-40).

\section{Conflicts of interest/Competing interests}

The authors declare that they have no competing interests. 
Availability of data and material

No.

\section{Code availability}

No.

\section{Authors' contributions}

The authors' contributions are as follows. H. Huang and J. Xie conceived and designed the experiments. C. Wang and M. Fu performed the experiments. C. Wang analyzed the data and wrote the paper. Xie polished the manuscript. All authors have participated sufficiently in the work to take public responsibility for the appropriateness of the experimental design and method, and the collection, analysis, and interpretation of the data. We have reviewed the final version of the manuscript and approve it for publication.

\section{Ethics approval}

All experimental procedures on animals were approved by the Institutional Animal Care and Use Committee at Fujian Medical University.

\section{Consent to participate}

Not applicable.

\section{Consent for publication}

Not applicable.

\section{Acknowledgments}

This study was supported by Natural Science Foundation of Fujian Province, China (No. 2018J05134, 2018J05131 and 2016J01769), Medical Minimally Invasive Center Program of Fujian Province, China (No. 2017-171) and Fujian Province health and family planning scientific research talent training project (No. 2018-CX-40).

\section{Compliance with Ethical Standards}

\section{Disclosure of potential conflicts of interest}

The authors declare that they have no potential conflicts of interest.

\section{Research involving Human Participants and/or Animals}


This research did not involve Human Participants. All experimental procedures on animals were approved by the Institutional Animal Care and Use Committee at Fujian Medical University.

\section{Informed consent}

Not applicable.

\section{References}

1. El Maalouf G, Le Tourneau C, Batty GN, Faivre S, Raymond, E (2009) Markers involved in resistance to cytotoxics and targeted therapeutics in pancreatic cancer. Cancer Treat Rev 35:167-174.

2. Wang C, Yang A, Zhang B, Yin Q, Huang H, Chen M, Xie J (2014) Pancreatic cancer PANC-1 cells growth inhibited by cucurmosin singly and combined with EGFR targeted drug. Pancreas 43:291-297.

3. Xie J, Wang C, Zhang B, Yang A, Yin Q, Huang H, Chen M (2013) Cucurmosin induces the apoptosis of human pancreatic cancer CFPAC-1 cells by inactivating the PDGFR- $\beta$ signalling pathway. Pharmacol Rep 65:682-688.

4. Xie J, Wang C, Yang A, Zhang B, Yin Q, Huang H, Chen M (2013) Cucurmosin kills human pancreatic cancer SW-1990 cells in vitro and in vivo. Anticancer Agents Med Chem 13:952-956.

5. Zhang B, Huang H, Xie J, Xu C, Chen M, Wang C, Yang A, Yin Q (2012) Cucurmosin induces apoptosis of BxPC-3 human pancreatic cancer cells via inactivation of the EGFR signaling pathway. Oncol Rep 27:891-897.

6. Wang C, Zhang W, Fu M, Yang A, Huang H, Xie J (2015) Establishment of human pancreatic cancer gemcitabine-resistant cell line with ribonucleotide reductase overexpression. Oncol Rep 33:383-390.

7. Endo Y, Mitsui K, Motizuki M, Tsurugi K (1987) The mechanism of action of ricin and related toxic lectins on eukaryotic ribosomes. The site and the characteristics of the modification in $28 \mathrm{~S}$ ribosomal RNA caused by the toxins. J Biol Chem 262:5908-5912.

8. Xu C, Huang H, Chen M, Xie J (2012) Effects of Cucurmosin on the Cell Proliferation and Apoptosis in Human Pancreatic PANG-1 Cells. Chin J Integr Tradit West Med 32:234-238.

9. Xie J, Yang A, Zhang B, Huang H, Chen M, Wang C (2012) Proliferation Inhibition and Apoptosis Induction of Cucurmosin on Human Pancreatic Cancer CFPAC-1 Cells. Chin Pharm J 47:956-959.

10. Yin Q, Huang H, Xie J, Chen M, Zhang B, Wang C (2011) Effects of Cucurmosin on Apoptosis in Human Pancreatic Cancer Cell Line SW1990. Chin J Bases Clin Gen Surg 18:380-383.

11. Goan YG, Zhou B, Hu E, Mi S, Yen Y (1999) Overexpression of ribonucleotide reductase as a mechanism of resistance to 2,2-difluorodeoxycytidine in the human KB cancer cell line. Cancer Res 59:4204-4207.

12. Cantley LC (2002) The Phosphoinositide 3-Kinase pathway. Science 296:1655-1657.

13. Huang J, Manning BD (2009) A complex interplay between Akt, TSC2 and the two mTOR complexes. Biochem Soc Trans 37:217-222. 
14. Corradetti MN, Guan KL (2006) Upstream of the mammalian target of rapamycin: do all roads pass through mTOR? Oncogene 25:6347-6360.

\section{Tables}

Table 1 SRB was used to detected the inhibitory rate of PANC-1RG7 cell line with different concentrations of GEM and CUS, and the synergistic index $Q$ value of the two drugs was calculated.

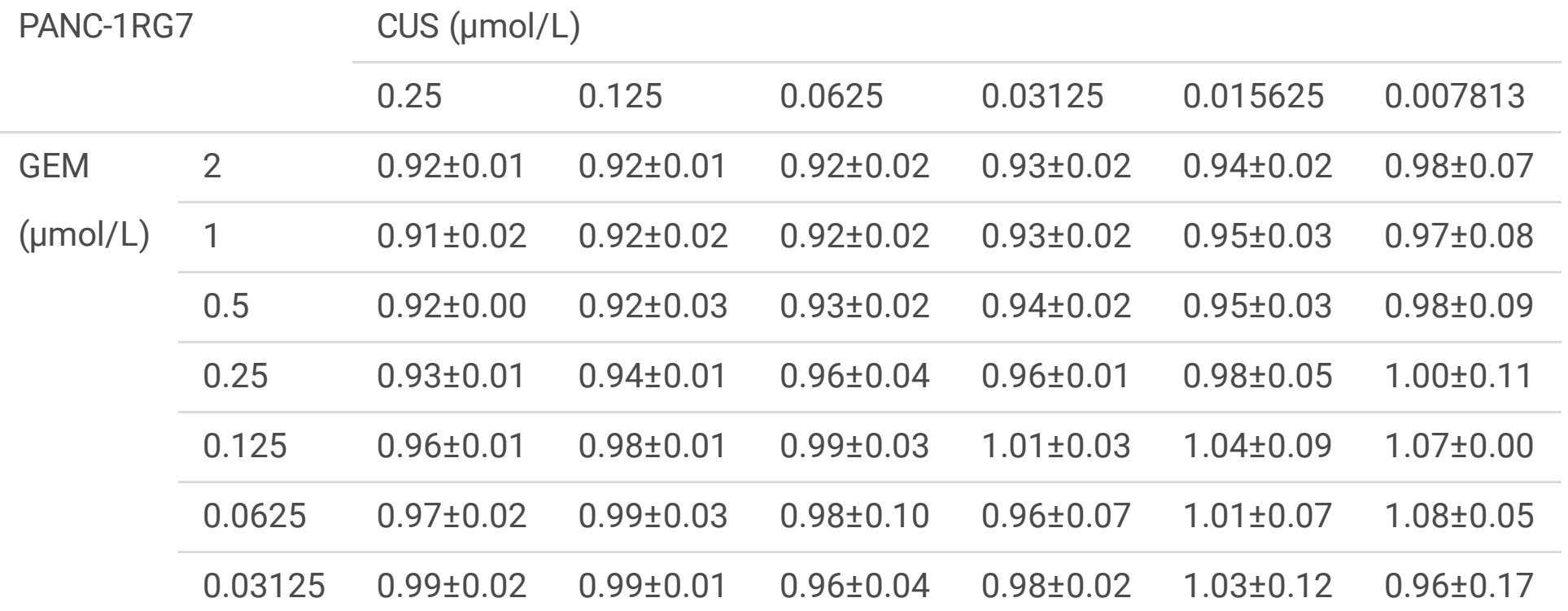

Table 2 Colony formation assaywas used to detected the inhibitory rate of PANC-1RG7 cell line with different concentrations of GEM and CUS, and the synergistic index Q value of the two drugs was calculated.

\begin{tabular}{|c|c|c|c|c|}
\hline \multirow[t]{2}{*}{ PANC-1RG7 } & & \multicolumn{3}{|c|}{ GEM $₫ \mu \mathrm{mol} / \mathrm{L} \rrbracket$} \\
\hline & & 0.0025 & 0.000625 & 0.000156 \\
\hline \multirow[t]{2}{*}{ CUS $(\mu \mathrm{mol} / \mathrm{L})$} & 0.01 & $1.02 \pm 0.01$ & $1.02 \pm 0.02$ & $1.01 \pm 0.02$ \\
\hline & 0.0025 & $0.98 \pm 0.02$ & $0.91 \pm 0.02$ & $0.92 \pm 0.01$ \\
\hline
\end{tabular}

Table 3 Subcutaneous tumors were completely peeled off after the mice were executed at $33 \mathrm{~d}$. Subcutaneous tumor weight of each group of mice with pancreatic cancer is shown $(n=10$, mean \pm SD).

\begin{tabular}{llll} 
Tumor weight $(\mathrm{g})$ & Control & CUS $0.5 \mathrm{mg} / \mathrm{kg}$ & CUS $1 \mathrm{mg} / \mathrm{kg}$ \\
\hline PANC-1 & $0.2118 \pm 0.0521$ & $0.2163 \pm 0.0833$ & $0.1368 \pm 0.0776^{\star}$ \\
\hline PANC-1 RG7 & $0.3247 \pm 0.1292^{\#}$ & $0.2143 \pm 0.0767 *$ & $0.1767 \pm 0.0989 * \#$
\end{tabular}

* Compared with Control Group, $\mathrm{p}<0.05$; \# Compared with PANC-1, $\mathrm{p}<0.05$. 
Table 4 The inhibitory rate of PANC-1 and PANC-1 RG7 subcutaneous implantation tumors after CUS intervention was shown.

\begin{tabular}{lll} 
Inhibitory rate (\%) & CUS $0.5 \mathrm{mg} / \mathrm{kg}$ & CUS $1 \mathrm{mg} / \mathrm{kg}$ \\
\hline PANC-1 & 22.18 & 35.39 \\
\hline PANC-1RG7 & 34.00 & 45.56
\end{tabular}

\section{Figures}

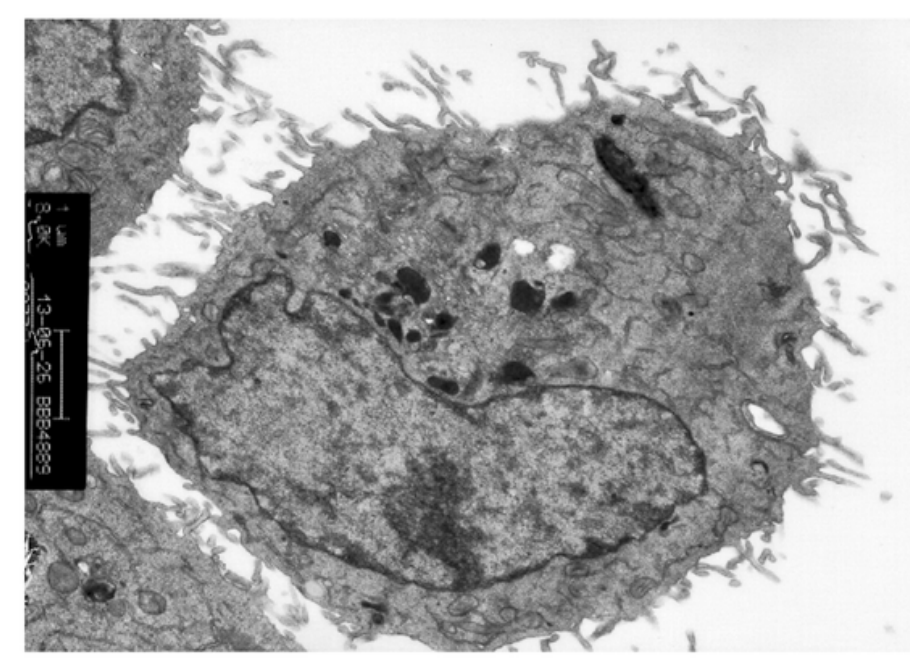

Before CUS intervention

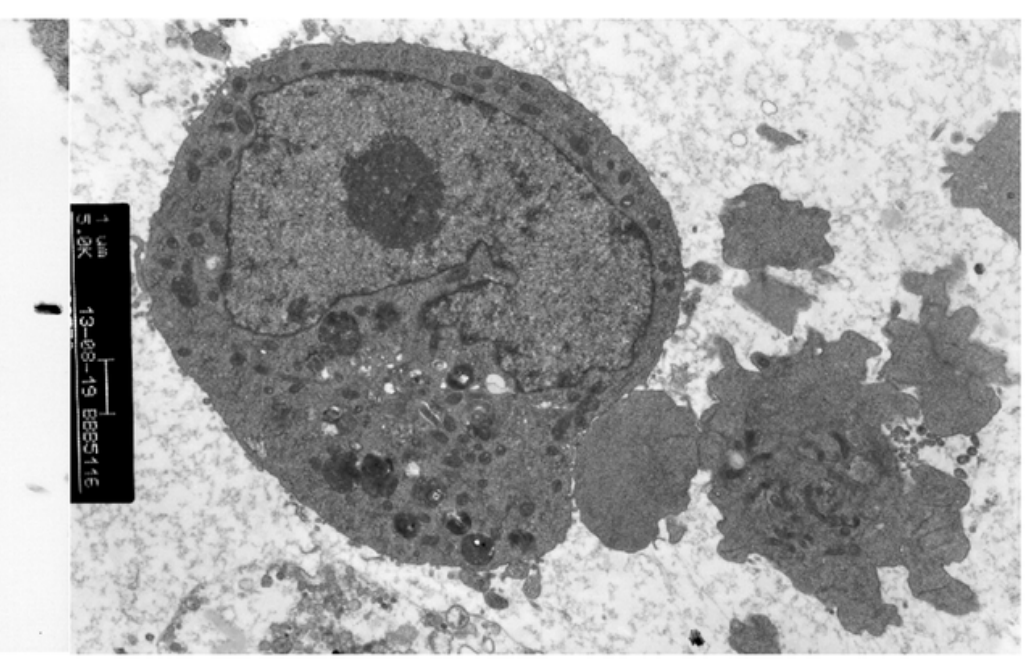

After CUS intervention

\section{Figure 1}

Morphological changes in GEM-resistant pancreatic cancer PANC-1RG7 cell before and after CUS intervention were observed under a transmission electron microscope. PANC-1RG7 cells were obviously apoptotic with large number of vacuoles and apoptotic bodies after CUS intervention.
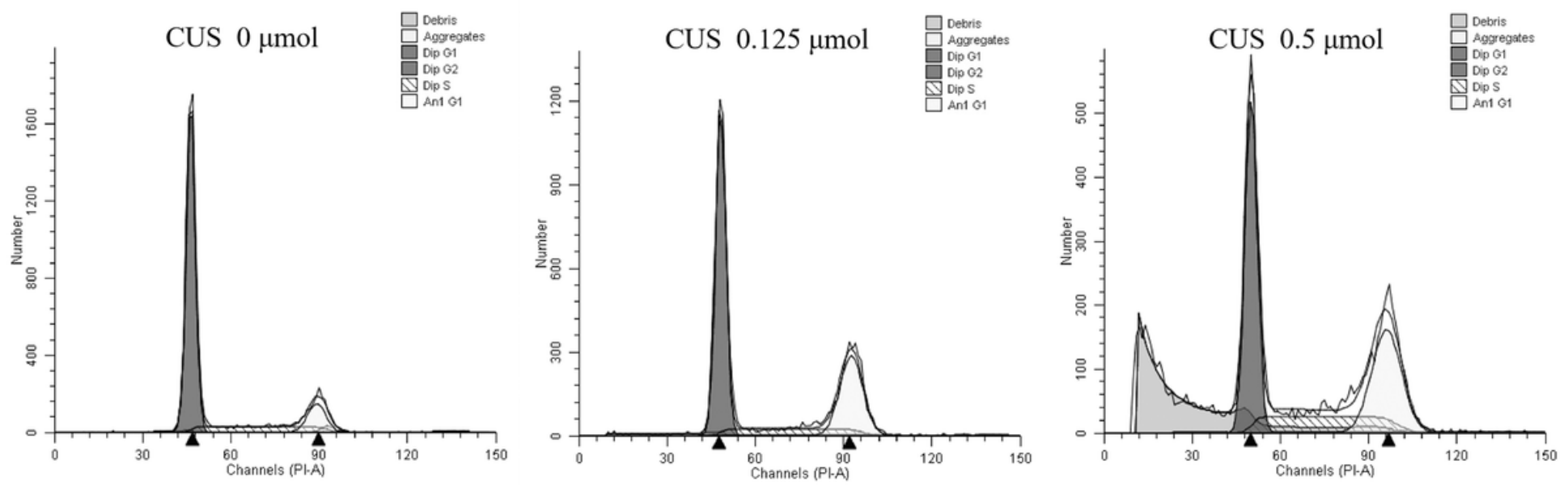

Figure 2 
PANC-1RG7 cells were detected by flow cytometric analysis for their DNA content and apoptosis after CUS intervention. No significant change in the cell ratio was shown in G0/G1, S and G2/M phase of PANC-1RG7, but apoptotic peak were observed.

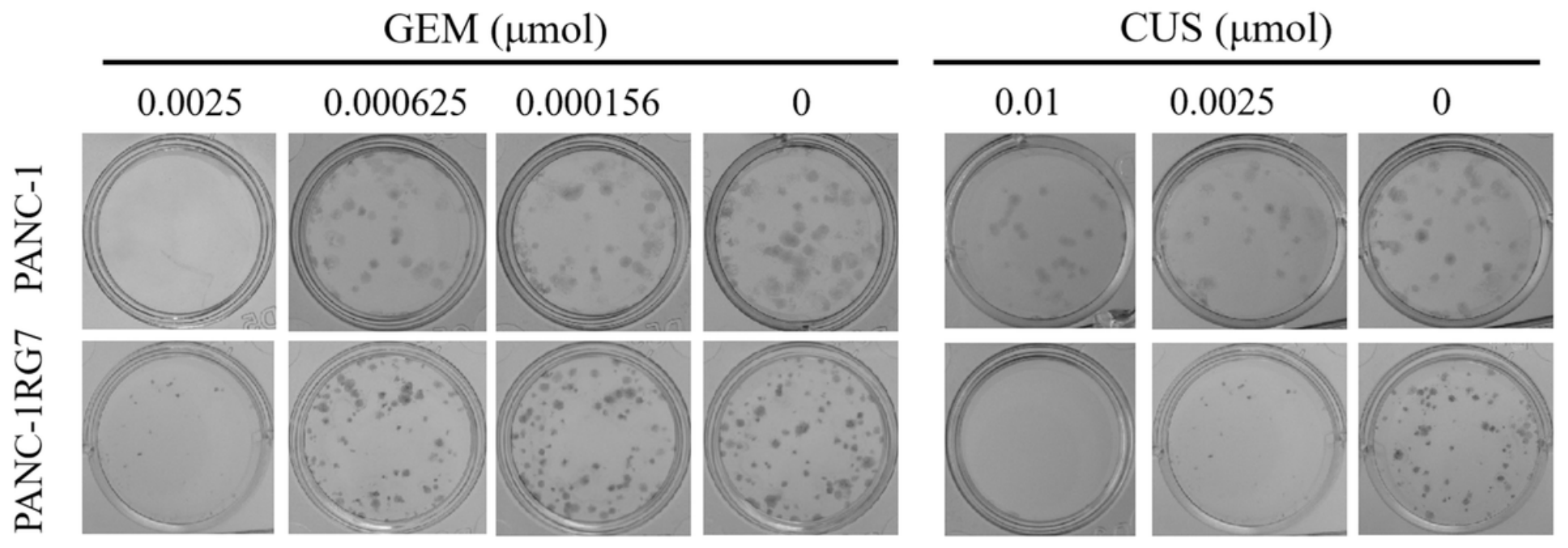

\section{Figure 3}

Cell colonies were counted following Giemsa staining. CUS and GEM inhibited proliferation in a dosedependent manner . PANC-1RG7 is more sensitive to CUS than its parent cells. 


\section{PANC-1RG7}

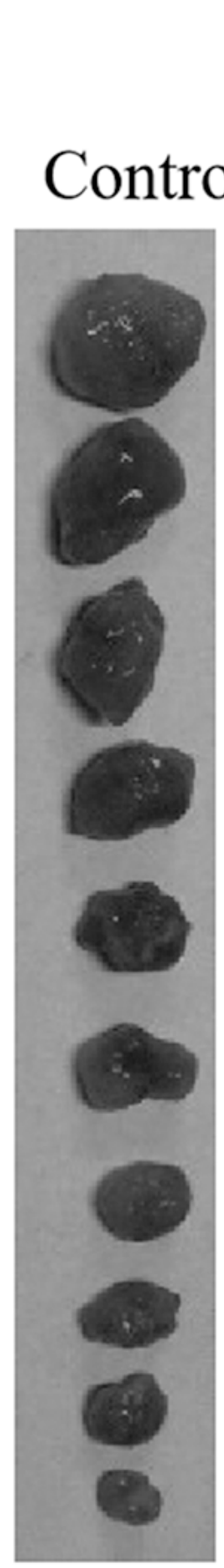

\section{CUS (mg/kg)}

0.5

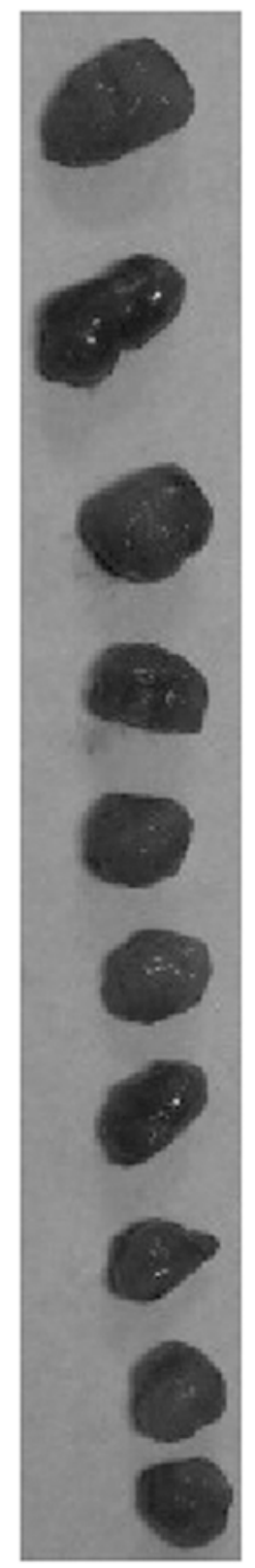

1

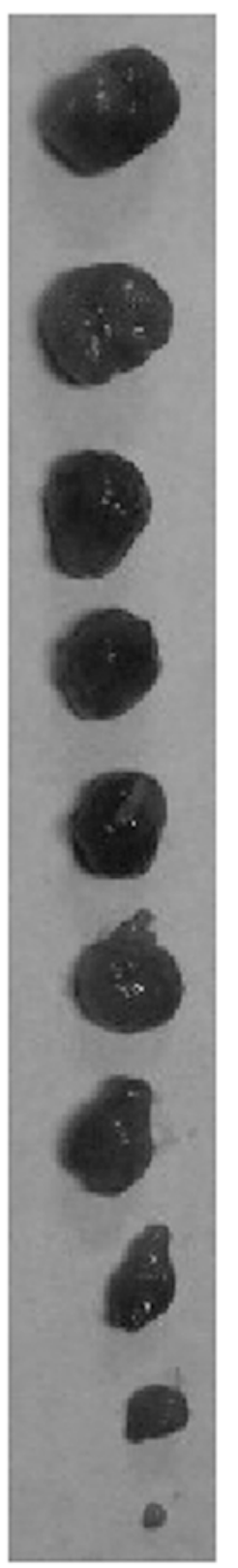

CUS (mg/kg)

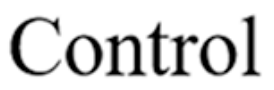

0.5
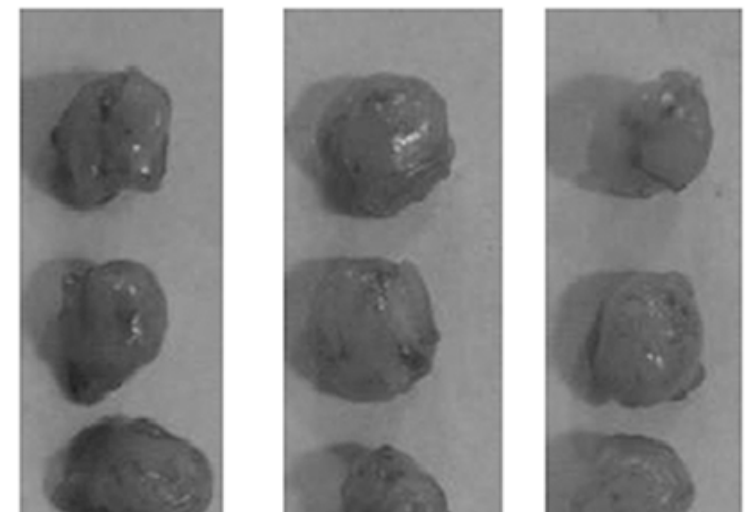$$
\text { . }
$$
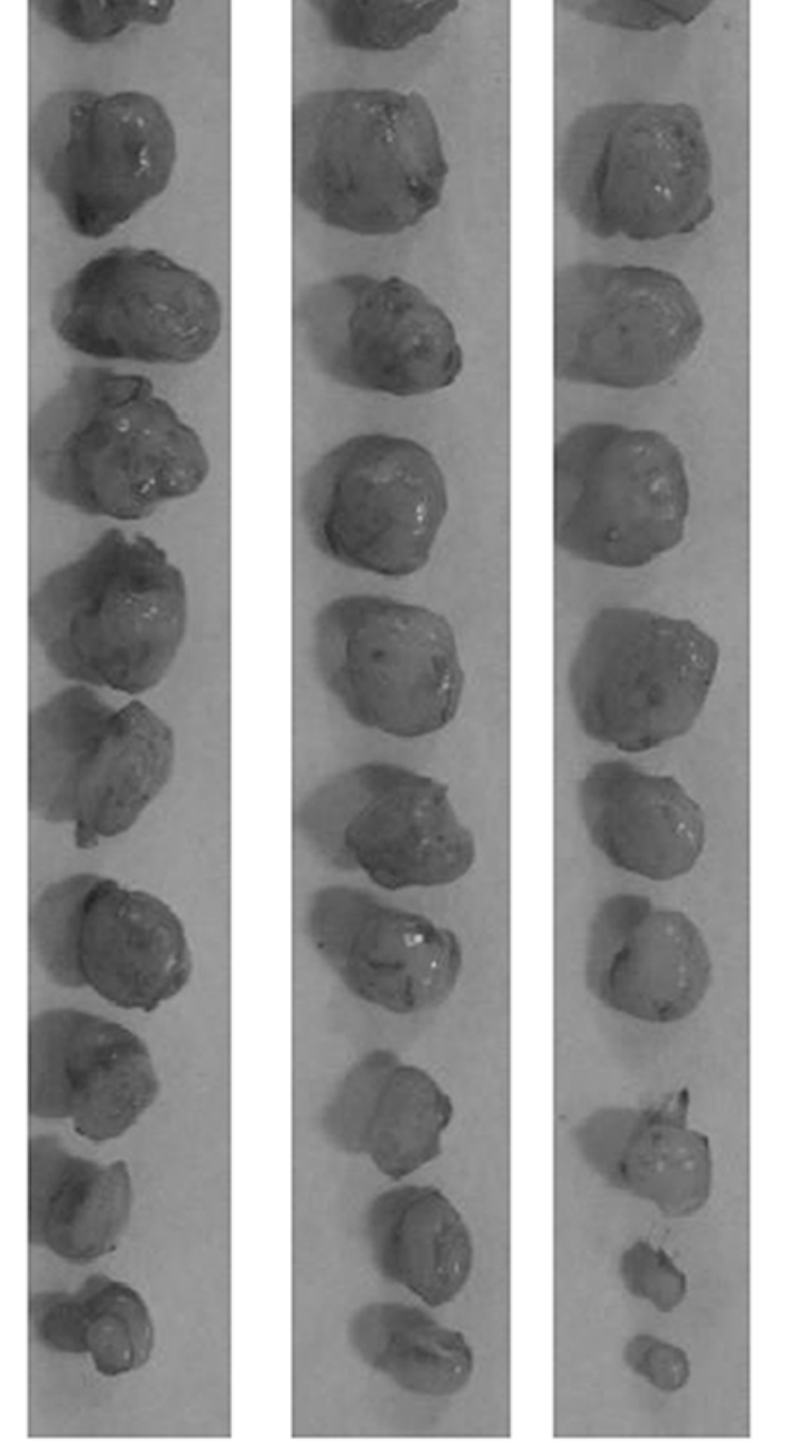

Figure 4

Subcutaneous tumors of PANC-1RG7 cells were completely peeled off and weighed. CUS can inhibit PANC-1 and PANC-1RG7 cell growth in a dose-dependent manner in vivo. 


\section{CUS $(\mu \mathrm{mol} / \mathrm{L})$}
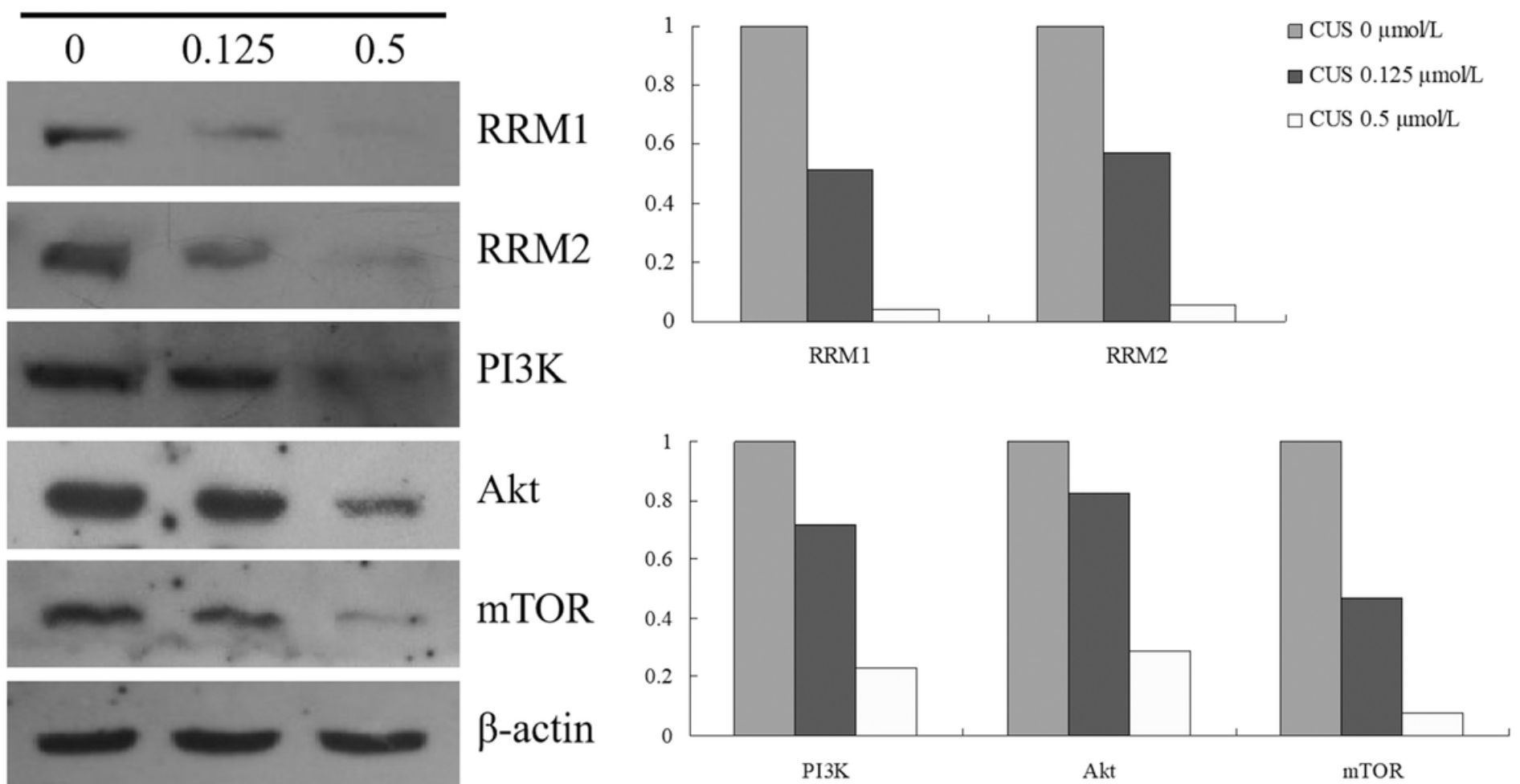

\section{Figure 5}

Western blot was used to detected some protein expressions in PANC-1RG7 cells after CUS intervention. With increasing CUS concentrations, the protein expressions of RRM1, RRM2, PI3K, Akt, and mTOR were gradually reduced. Gray scales shown on the right indicate comparison with beta-actin, showing CUS inhibits the signal transduction of the PI3K/Akt/mTOR signaling pathway. 